\title{
Association between social support and place of delivery: a cross-sectional study in Kericho, Western Kenya
}

\author{
Mayo Ono ${ }^{1 *}$, Akiko Matsuyama², Mohamed Karama ${ }^{3}$ and Sumihisa Honda ${ }^{1}$
}

\begin{abstract}
Background: An estimated 358,000 maternal deaths still occur worldwide each year. The place of delivery is of great significance to the reduction of maternal mortality. Moreover, socio-economic factors, cultural traits, and local customs are associated with health-seeking behavior. This study aimed to explore determinants of association between social support and place of delivery.

Methods: This cross-sectional study was conducted from September to November 2011 at Sosiot Health Center, Kericho West District, Kenya. Participants were 303 mothers who brought their babies to the health center for immunization within their first year of life. Women underwent a structured interview using a questionnaire on demographic characteristics and their experiences of delivery including place of delivery and social support.

Results: The proportion of deliveries at health facilities was significantly higher in unmarried than married women ( $93 \%$ and $78 \%$, respectively; $P=0.008$ ). Unmarried women whose mothers supported them in housework and whose sisters helped them fetch water were more likely to deliver at health facilities $(P=0.002$ and 0.042 , respectively) than those without this support. However, married women whose husbands supported them in farming and whose neighbors helped them fetch water were less likely to deliver at health facilities $(P=0.003$ and 0.021 , respectively) than those without this support. Married women who were advised to deliver at a health facility by their mother-in-law or health staff were more likely to deliver at health facilities ( $P=0.015$ and 0.022 , respectively) than those who did not receive this advice. Multivariate analysis revealed that married women were more likely to deliver at health facilities if they were highly educated (odds ratio $[O R]=2.5)$; had financial capability $(O R=4.3)$; had medical insurance $(\mathrm{OR}=4.2)$; were primiparous $(\mathrm{OR}=3.5)$; did not have the support of sisters-in-law for fetching water $(\mathrm{OR}=2.2)$; or were advised to deliver at a health facility by family or neighbors $(\mathrm{OR}=2.5)$.
\end{abstract}

Conclusions: Promotion of delivery at health facilities requires approaches that consider women's social situation, since factors influencing place of delivery differ for married and unmarried women.

Keywords: Kenya, Maternal health, Place of delivery, Social support

\section{Background}

An estimated 358,000 maternal deaths still occur worldwide each year [1]. Most of these deaths occur during labor, delivery, or the first 24 hours postpartum, and most complications cannot be predicted or prevented [2]. Where women deliver, who attends them, and how quickly they can be transported to referral-level care are

\footnotetext{
* Correspondence: mayonoko@gmail.com

'Graduate School of Biomedical Sciences, Nagasaki University, 1-12-4 Sakamoto, Nagasaki 852-8523, Japan

Full list of author information is available at the end of the article
}

thus crucial factors in determining the ability to successfully intervene [3]. The general pattern of utilization of maternal health services contributes to the incidence of maternal mortality and morbidity [4]. However, many women do not have access to the services they need for various reasons. Moreover, socio-economic factors, cultural traits, and local customs are associated with health-seeking behavior. For instance, there are places where services are available but women do not make use of them [3]. Women may prefer to stay at home for a delivery so that they can take care of family members

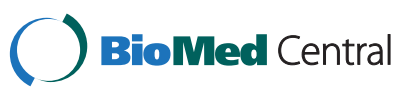


such as young children or elderly relatives and manage their daily household chores [5]. Previous studies have shown that several factors are predictors of women accessing health services [6,7]. It is important to identify which factors lead women to deliver at health facilities. Social support is also an important variable influencing health [8]. However, little attention has been paid to the possible association between social support and place of delivery. The aim of the present study was to determine the association between social support and place of delivery, and other factors influencing delivery location.

\section{Place of delivery and types of birth attendant in Kenya}

Delivery with skilled birth attendants is critical to the reduction of maternal mortality [3]. In Kenya, $43.8 \%$ of laboring women were assisted by skilled birth attendants, and $42.6 \%$ delivered at health facilities between 2008 and 2009 [9]. The place of delivery, for example, health facility or home, is of great significance: home births are associated with increased maternal mortality, since women delivering at home do not have access to the professional assistance provided in facilities. In Kenya, the National Reproductive Health Policy (2007) has brought about a paradigm shift towards a focus on skilled birth attendants for all pregnant women, thus necessitating a policy change regarding traditional birth attendants (TBAs) as providers of delivery services [10]. However, TBAs continue to play a vital role in delivery, assisting with $27.6 \%$ of births. Moreover, relatives and friends assist with $21.2 \%$ of deliveries between 2008 and 2009 [9]. In Kericho, the location of the present study, the proportion of women delivering at a health facility remained at $50 \%$ in 2007 [11], a proportion considered inadequate.

\section{Social support}

Social support from a spouse or partner and a social network of family and friends has the potential to influence women's decisions regarding obtaining prenatal care [12]. As in most societies, women have traditionally relied on other women for social support during pregnancy, childbirth, and breastfeeding [13,14]. Female relatives and friends accompany laboring women to maternity units [15], and the presence of a female relative during labor is associated with improved labor outcomes [16].

Social support has been measured in numerous ways. One frequent criticism of research in this area is the lack of consensus about social support in terms of its definition and how best to measure it [17-19]. House, a sociologist, specified that potential forms of social support were emotional support, appraisal support, informational support, and instrumental support [18]. Schaefer classified social support into tangible, emotional, and informational support, and he focused on relationships between these types of social support [19]. A previous study found that social support is related to health behaviors [12], and absence of social support was associated with increased maternal mortality [20]. To obtain a better understanding of the effect of social support on place of delivery, the source and types of social support should be considered.

\section{The Kenyan context}

Maternal mortality in Kenya remains high at 488 per 100,000 live births in 2008-09 [9]. Kericho District (comprising East and West Kericho) is located about $260 \mathrm{~km}$ from the capital, Nairobi. Kericho District has a population of 503,468 [21]. This district had nine hospitals, 11 health centers, five health clinics, one maternity nursing home, and 97 dispensaries [11]. The doctor/patient ratio was $1: 15,000$, and $40 \%$ of houses were located within $15 \mathrm{~km}$ from health facilities [21].

\section{Methods}

\section{Subjects}

This cross-sectional study was conducted from September to November 2011 at Sosiot Health Center, Kericho West, Kenya. Information was obtained by means of a structured interview using a questionnaire. Kericho was one of the target districts of two recent community health projects aimed at improving maternal and neonatal health. Those projects were implemented by the Kenyan Government in collaboration with the Japan International Cooperation Agency (JICA) and a Japanese non-profit organization, Health and Development Service (HANDS). Promotion of delivery at health facilities was included in the message of the one of those projects [11]. Sosiot Health Center was involved in both of these projects. The center is situated beside a major thoroughfare, and is a 15 to 20 minute car journey from the center of commerce in Kericho. The target population of this health center was 43,493 people [11], making it a larger scale center than other health facilities in this region.

\section{Questionnaire}

The respondents were 306 mothers aged 18 to 49, who brought their babies to Sosiot Health Center for immunization within their first year of life, from September to November 2011. We excluded from the analysis two respondents who delivered on the way to the health facility and one respondent who did not answer the question on marital status. Thus data from 303 respondents (99\%) were analyzed. Local people who were at least high school graduates and spoke English, Kiswahili (the national language), and Kipsigis (the dominant language spoken at the study site) fluently were hired as research assistants. They were trained by the researcher so that they conducted interviews smoothly and protected respondents' privacy. The interviews were 
Table 1 Socio-demographic characteristics and birth experience $(\mathrm{N}=303)$

\begin{tabular}{|c|c|c|c|}
\hline \multicolumn{2}{|l|}{ Variable } & Median & Range \\
\hline \multicolumn{2}{|l|}{ Maternal age (years) } & 23 & $18-41$ \\
\hline \multicolumn{2}{|l|}{ Infant age (months) } & 4 & $0-12$ \\
\hline & & $\mathrm{N}$ & $\%$ \\
\hline \multirow[t]{2}{*}{ Tribe } & Kipsigis & 294 & 97.0 \\
\hline & Others & 9 & 3.0 \\
\hline \multirow[t]{6}{*}{ Education level } & Lower primary & 43 & 14.2 \\
\hline & Primary & 124 & 40.9 \\
\hline & Vocational & 1 & 0.3 \\
\hline & Secondary & 105 & 34.7 \\
\hline & College & 25 & 8.3 \\
\hline & University & 5 & 1.7 \\
\hline \multirow[t]{5}{*}{ Occupation } & Farmer & 251 & 82.8 \\
\hline & Self-employed & 19 & 6.3 \\
\hline & Private employee & 16 & 5.3 \\
\hline & Government employee & 12 & 4.0 \\
\hline & Student & 5 & 1.7 \\
\hline \multirow[t]{2}{*}{ Marital status } & Married/Cohabiting & 245 & 80.9 \\
\hline & Unmarried & 58 & 19.1 \\
\hline Economic status & 0 & 6 & 2.0 \\
\hline \multirow[t]{6}{*}{ (Household assets) } & 1 & 31 & 10.2 \\
\hline & 2 & 64 & 21.1 \\
\hline & 3 & 70 & 23.1 \\
\hline & 4 & 52 & 17.2 \\
\hline & 5 & 78 & 25.7 \\
\hline & 6 & 2 & 0.7 \\
\hline \multirow[t]{3}{*}{ Medical insurance } & Yes & 83 & 27.4 \\
\hline & No & 219 & 72.3 \\
\hline & Unknown & 1 & 0.3 \\
\hline \multirow{2}{*}{$\begin{array}{l}\text { Time to reach the } \\
\text { nearest delivery facility }\end{array}$} & Less than 20 minutes & 140 & 46.2 \\
\hline & 20 minutes or more & 163 & 53.8 \\
\hline \multirow[t]{2}{*}{ Place of delivery } & Health facility & 245 & 80.9 \\
\hline & Home & 58 & 19.1 \\
\hline \multirow{7}{*}{$\begin{array}{l}\text { Type of facility where } \\
\text { delivery took place }\end{array}$} & Health center & 147 & 60.0 \\
\hline & District hospital & 69 & 28.2 \\
\hline & Private hospital/Clinic & 24 & 9.8 \\
\hline & Dispensary & 1 & 0.4 \\
\hline & Sub-district hospital & 1 & 0.4 \\
\hline & National hospital & 1 & 0.4 \\
\hline & Others & 2 & 0.8 \\
\hline \multirow{3}{*}{$\begin{array}{l}\text { Type of birth attendant } \\
\text { at home birth }\end{array}$} & Mother-in-law & 26 & 44.8 \\
\hline & Neighbor & 15 & 25.9 \\
\hline & Traditional birth attendant & 4 & 6.9 \\
\hline
\end{tabular}

Table 1 Socio-demographic characteristics and birth experience $(\mathbf{N}=303)$ (Continued)

\begin{tabular}{llrr}
\hline & Sister-in-law & 4 & 6.9 \\
& Mother & 2 & 3.4 \\
Grandmother & 1 & 1.7 \\
& Female relative & 1 & 1.7 \\
Parity & Unknown & 5 & 8.6 \\
& Primiparous & 143 & 47.2 \\
& Multiparous & 160 & 52.8 \\
\hline
\end{tabular}

conducted at Sosiot Health Center. The questionnaire was constructed to ascertain the demographic characteristics of the subjects, as well as their experiences of delivery including place of delivery and social support (see Additional files 1, 2 and 3).

\section{Dependent variable}

The primary dependent variable was the place of delivery of the latest child, dichotomized as health facility or home. Health facility deliveries included those at the dispensary, health center, sub-district hospital, district hospital, national hospital, and private hospital/clinic.

\section{Demographic and birth experience variables}

We collected data relating to maternal age, infant age, tribe, education level, occupation, marital status, economic status, medical insurance, the time required to reach the nearest delivery facility, types of birth attendant for home delivery, and parity. Information on household assets (clock or watch, electricity, radio, television, mobile telephone, non-mobile telephone, refrigerator, and solar panel) was used to derive a wealth index using the Kenya DHS [9]. Respondents were categorized into three levels by the wealth index. The time required to travel to the nearest delivery facility was calculated in terms of total minutes by foot, bike, shared taxi, and private car or taxi. Respondents were then divided into two groups by the median travel time.

\section{Social support variables}

Social support was measured in terms of: 1) Support for daily tasks (housework, fetching water, and farming), and 2) Advice to deliver in a health facility. Support for daily tasks indicated instrumental support, and advice regarding facility delivery reflected informational support. 1) Respondents were asked if they had support for housework, fetching water, and farming, and by whom. They chose from the following answers: husband, mother-in-law, mother, father-in-law, father, sisters-inlaw, sisters, brothers-in-law, brothers, female relatives, children, friends, neighbors, domestic servants, co-wives, 
and others. 2) Respondents were asked whether somebody had advised them to deliver at a health facility. They chose from the following answers: husband, mother-in-law, mother, father-in-law, father, sisters-in-law, sisters, female relatives, children, friends, neighbors, domestic servants, co-wives, health staff, and others.

\section{Ethical considerations}

All women who participated provided written informed consent after reading through the consent form with the interviewer. They were informed that they had the right to refuse participation or to withdraw from this study at any time without prejudice to themselves. This study was approved by the ethics committees of Nagasaki University (Nagasaki, Japan) in December 2010 and Kenya Medical Research Institute (Nairobi, Kenya) in July 2011.

\section{Data analysis}

The chi-square test was used for nominal scale data, whereas the Cochran-Armitage trend test was used for ordinal scale data. The simultaneous effects of factors on facility delivery were analyzed using linear logistic models. The following factors were included in stepwise logistic regression: age, education level, occupation, economic status, medical insurance, the time required to travel to the nearest delivery facility, support of motherin-law for household work, support of husband for farming, support of sisters-in-law for fetching water, advice on facility delivery from family or neighbors, advice on facility delivery from health staff, and parity. Odds ratios (OR) with 95\% confidence intervals (CI) were calculated. IBM SPSS Statistics Version 21 was used for statistical analysis (SPSS Inc, Chicago, IL, USA).

\section{Results}

Socio-demographic characteristics and birth experience are shown in Table 1. Among the 303 respondents, age ranged from 18 to 41 years and median age was 23 years. Around $86 \%$ of respondents had some primary education. The most common occupation was farming. About $97 \%$ of women were Kipsigis, and more than $80 \%$ of respondents were married. In their most recent delivery, 58 (19.1\%) women delivered at home and 245 (80.9\%) delivered at health facilities. Just less than half of women who delivered at home were assisted by their mother-in-law, and the next largest proportion was assisted by neighbors.

Table 2 presents the associations between sociodemographic characteristics and place of delivery. Bivariate analysis indicated that facility delivery was more likely in younger women $(\mathrm{P}=0.002)$, unmarried women $(\mathrm{P}=0.008)$, primiparae $(\mathrm{P}<0.001)$ and those with financial capability or high educational attainment $(\mathrm{P}<0.001)$.

Table 3 shows associations between support for daily tasks and place of delivery among married women.
Table 2 Associations between socio-demographic characteristics and place of delivery $(\mathrm{N}=303)$

\begin{tabular}{|c|c|c|c|c|c|}
\hline & \multicolumn{2}{|c|}{$\begin{array}{c}\text { Home } \\
\text { delivery } \\
(\mathrm{N}=58)\end{array}$} & \multicolumn{2}{|c|}{$\begin{array}{c}\text { Facility } \\
\text { delivery } \\
(\mathrm{N}=245)\end{array}$} & \multirow[b]{2}{*}{ P-value } \\
\hline & $\mathrm{N}$ & $\%$ & $\mathrm{~N}$ & $\%$ & \\
\hline \multicolumn{6}{|l|}{ Maternal age } \\
\hline 18-25 (years) & 31 & 14.4 & 184 & 85.6 & \\
\hline 26-30 (years) & 20 & 30.3 & 46 & 69.7 & \\
\hline$\geq 31$ (years) & 7 & 31.8 & 15 & 68.2 & $0.002^{\mathrm{a}}$ \\
\hline \multicolumn{6}{|l|}{ Education level } \\
\hline Primary or lower & 47 & 28.1 & 120 & 71.9 & \\
\hline Secondary/Nocational & 10 & 9.4 & 96 & 90.6 & \\
\hline College/University & 1 & 3.3 & 29 & 96.7 & $<0.001^{\mathrm{a}}$ \\
\hline \multicolumn{6}{|l|}{ Occupation } \\
\hline Farmers & 55 & 21.9 & 196 & 78.1 & \\
\hline Others & 3 & 5.8 & 49 & 94.2 & $0.007^{b}$ \\
\hline \multicolumn{6}{|l|}{ Marital status } \\
\hline Married/Cohabiting & 54 & 22.0 & 191 & 78.0 & \\
\hline Unmarried & 4 & 6.9 & 54 & 93.1 & $0.008^{b}$ \\
\hline \multicolumn{6}{|l|}{$\begin{array}{l}\text { Economic status } \\
\text { (Household asset score) }\end{array}$} \\
\hline $0-1$ & 16 & 43.2 & 21 & 56.8 & \\
\hline $2-3$ & 31 & 23.1 & 103 & 76.9 & \\
\hline$\geq 4$ & 11 & 8.3 & 121 & 91.7 & $<0.001^{a}$ \\
\hline \multicolumn{6}{|l|}{ Medical insurance } \\
\hline Yes & 8 & 9.6 & 75 & 90.4 & \\
\hline No & 50 & 22.8 & 169 & 77.2 & $0.009^{b}$ \\
\hline Unknown & 0 & & 1 & & \\
\hline \multicolumn{6}{|c|}{$\begin{array}{l}\text { Time to reach the nearest } \\
\text { delivery facility }\end{array}$} \\
\hline Less than 20 minutes & 22 & 15.7 & 118 & 84.3 & \\
\hline 20 minutes or more & 36 & 22.1 & 127 & 77.9 & $0.16^{\mathrm{b}}$ \\
\hline \multicolumn{6}{|l|}{ Parity } \\
\hline Primiparous & 13 & 8.1 & 147 & 91.9 & \\
\hline Multiparous & 45 & 31.5 & 98 & 68.5 & $<0.001^{\mathrm{b}}$ \\
\hline
\end{tabular}

${ }^{\mathrm{a} C o c h r a n-A r m i t a g e}$ trend test ${ }^{\mathrm{b}} \mathrm{Chi}$-square Test.

Married women whose husbands supported them in farming and whose neighbors helped them fetching water were less likely to deliver at health facilities $(\mathrm{P}=$ 0.003 and $\mathrm{P}=0.021$, respectively) than those whose husbands and neighbors did not provide this support.

Table 4 shows associations between support for daily tasks and place of delivery among unmarried women. Unmarried women whose mothers supported them in housework and those whose sisters helped them fetch water were significantly more likely to deliver at health facilities ( $\mathrm{P}=0.002, \mathrm{P}=0.042$, respectively) than those whose mothers and sisters did not provide this support. 
Table 3 Associations between support for daily tasks and place of delivery among married women

\begin{tabular}{|c|c|c|c|c|c|c|c|c|c|c|c|c|c|c|c|}
\hline & \multicolumn{5}{|c|}{$\begin{array}{l}\text { Support with housework } \\
\qquad(\mathrm{N}=\mathbf{2 4 5})\end{array}$} & \multicolumn{5}{|c|}{$\begin{array}{l}\text { Support with fetching water } \\
\qquad(\mathrm{N}=231)^{\mathrm{a}}\end{array}$} & \multicolumn{5}{|c|}{$\begin{array}{l}\text { Support with farming } \\
\qquad(\mathrm{N}=229)^{\mathrm{b}}\end{array}$} \\
\hline & \multicolumn{2}{|c|}{$\begin{array}{l}\text { Home delivery } \\
\qquad(\mathrm{N}=54)\end{array}$} & \multicolumn{2}{|c|}{$\begin{array}{l}\text { Facility delivery } \\
\qquad(\mathrm{N}=191)\end{array}$} & \multirow[b]{2}{*}{ P-value ${ }^{c}$} & \multicolumn{2}{|c|}{$\begin{array}{l}\text { Home delivery } \\
\qquad(\mathrm{N}=51)\end{array}$} & \multicolumn{2}{|c|}{$\begin{array}{l}\text { Facility delivery } \\
\qquad(N=180)\end{array}$} & \multirow[b]{2}{*}{ P-value ${ }^{c}$} & \multicolumn{2}{|c|}{$\begin{array}{l}\text { Home delivery } \\
\qquad(\mathrm{N}=53)\end{array}$} & \multicolumn{2}{|c|}{$\begin{array}{l}\text { Facility delivery } \\
\qquad(N=176)\end{array}$} & \multirow[b]{2}{*}{ P-value } \\
\hline & $\mathrm{N}$ & $\%$ & $\mathbf{N}$ & $\%$ & & $\mathrm{~N}$ & $\%$ & $\mathrm{~N}$ & $\%$ & & $\mathbf{N}$ & $\%$ & $\mathrm{~N}$ & $\%$ & \\
\hline \multicolumn{16}{|c|}{ Support from mother-in-law } \\
\hline Yes & 29 & 20.4 & 113 & 79.6 & & 17 & 20.0 & 68 & 80.0 & & 5 & 20.0 & 20 & 80.0 & \\
\hline No & 25 & 24.3 & 78 & 75.7 & 0.473 & 34 & 23.3 & 112 & 76.7 & 0.561 & 48 & 23.5 & 156 & 76.5 & 0.693 \\
\hline \multicolumn{16}{|c|}{ Support from husband } \\
\hline Yes & 3 & 27.3 & 8 & 72.7 & & 1 & 5.0 & 19 & 95.0 & & 36 & 31.6 & 78 & 68.4 & \\
\hline No & 51 & 21.8 & 183 & 78.2 & 0.668 & 50 & 23.7 & 161 & 76.3 & 0.054 & 17 & 14.8 & 98 & 85.2 & 0.003 \\
\hline \multicolumn{16}{|c|}{ Support from sister-in-law } \\
\hline Yes & 17 & 25.0 & 51 & 75.0 & & 21 & 29.6 & 50 & 70.4 & & 4 & 40.0 & 6 & 60.0 & \\
\hline $\mathrm{No}^{\mathrm{d}}$ & 37 & 20.9 & 140 & 79.1 & 0.489 & 30 & 18.8 & 130 & 81.3 & 0.067 & 49 & 22.4 & 170 & 77.6 & 0.196 \\
\hline \multicolumn{16}{|c|}{ Support from mother } \\
\hline Yes & 0 & 0.0 & 3 & 100.0 & & 1 & 14.3 & 6 & 85.7 & & 0 & 0.0 & 1 & 100.0 & \\
\hline No & 54 & 22.3 & 188 & 77.7 & 0.354 & 50 & 22.3 & 174 & 77.7 & 0.614 & 53 & 23.2 & 175 & 76.8 & 0.582 \\
\hline \multicolumn{16}{|c|}{ Support from sister } \\
\hline Yes & 5 & 19.2 & 21 & 80.8 & & 3 & 11.5 & 23 & 88.5 & & 0 & 0.0 & 5 & 100.0 & \\
\hline $\mathrm{No}^{\mathrm{e}}$ & 49 & 22.4 & 170 & 77.6 & 0.715 & 48 & 23.4 & 157 & 76.6 & 0.169 & 53 & 23.7 & 171 & 76.3 & 0.215 \\
\hline \multicolumn{16}{|c|}{ Support from neighbor } \\
\hline Yes & 8 & 36.4 & 14 & 63.6 & & 26 & 30.2 & 60 & 69.8 & & 12 & 27.3 & 32 & 72.7 & \\
\hline No & 46 & 20.6 & 177 & 79.4 & 0.089 & 25 & 17.2 & 120 & 82.8 & 0.021 & 41 & 22.2 & 144 & 77.8 & 0.47 \\
\hline
\end{tabular}

Table 5 shows the associations between advice regarding facility delivery and place of delivery among married women. Married women who were advised by their mothers-in-law or by health staff to deliver at a health facility were more likely to do so $(\mathrm{P}=0.015, \mathrm{P}=0.022$, respectively) than those who were not.

Table 6 shows the associations between advice regarding facility delivery and place of delivery among unmarried women. There were no statistically significant differences between those who were advised to deliver at a health facility and those who were not.

Table 7 summarizes the results of multivariate logistic regression analysis of factors associated with the place of delivery in married women. Facility delivery was more likely among married women who were highly educated $(\mathrm{OR}=2.5, \mathrm{CI}: 1.0-6.1)$; who had financial capability $(\mathrm{OR}=$ 4.3, CI: $1.6-11.3)$; who had medical insurance $(\mathrm{OR}=4.2$, CI: 1.4 - 12.4); or who did not have previous birth experience $(\mathrm{OR}=3.5$, CI: $1.5-8.5)$. Facility delivery was also more likely among married women who did not have the support of sisters-in-law for fetching water $(\mathrm{OR}=2.2$, CI:
$1.0-4.7)$, or who were advised to deliver at a health facility by family or neighbors ( $\mathrm{OR}=2.5, \mathrm{CI}: 1.2-5.5)$.

\section{Discussion}

The present study found that more than $80 \%$ of women delivered at health facilities, and less than $20 \%$ delivered at home. This is a high proportion of facility deliveries and low proportion of home deliveries in comparison to findings of the Kenya DHS (national estimate, $42.6 \%$ facility deliveries and $56.2 \%$ home deliveries) [9]. We believe this is because a large public health intervention focusing on maternal health had recently involved the current study site, thereby increasing the proportion of facility deliveries. Moreover, respondents were mothers who brought their babies to the health center for immunization. Thus we might have selected those who had already easy access to health facilities. However, a high proportion of facility deliveries is not unusual in urban areas within sub-Saharan Africa. Progress towards the professionalization of childbirth attendance in the urban population was already good in 1992 (>70\% of 
Table 4 Associations between support for daily tasks and place of delivery among unmarried women

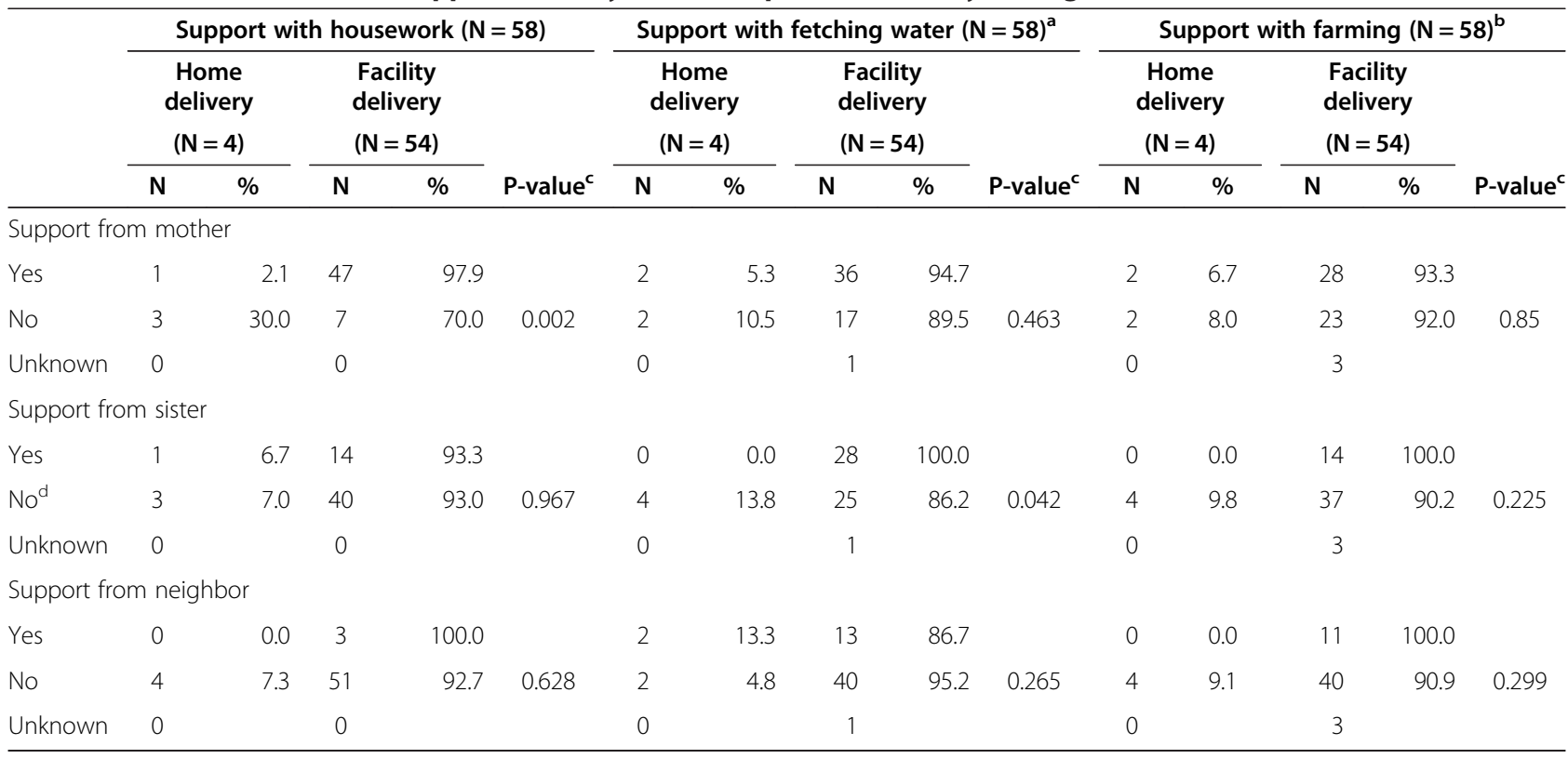

${ }^{a}$ Excluded women who did not have to fetch water because they had tap water.

${ }^{b}$ Excluded women who did not have to do farming because they had no farms or livestock.

${ }^{c}$ Chi-square test.

dincluded women who did not have any sisters and who therefore did not have support from sisters.

births were attended by health professionals) and even better in 2000 [3]. A similar rise in facility deliveries would have accompanied this, since most professional assistance is provided in health facilities. On the other hand, rural sub-Saharan Africa showed no improvement; $32 \%$ of deliveries were attended by health professionals in the early 1990s and this proportion remained the same in 2000 [3]. While the present study site is not located in an area as urbanized as Nairobi, the capital of Kenya, some of its characteristics are more similar to urban areas than to rural areas because of economic development accompanying the tea industry.

Bivariate analysis showed that place of delivery was associated with age, educational level, occupation, marital status, economic status, medical insurance cover, parity, support for daily tasks, and advice regarding facility delivery. Many studies have investigated factors influencing place of delivery. For instance, a study in Kenya [22] and one in Burkina Faso [23] reported that a high education level was associated with a high proportion of facility deliveries. Another study in African countries including Kenya showed that favorable economic status was a significant predictor of the proportion of facility deliveries [7]. Moreover, the present study found that women who had medical insurance were more likely to deliver at health facilities, in agreement with a previous study conducted in Kenya [24]. In addition, primiparae were significantly more likely than multiparae to deliver at health facilities, as in previous studies [25]. Women who have not previously given birth tend to be more worried about complications than those who have had previous deliveries; therefore, they tend to choose facility delivery.

The current findings showed that types of support and the people providing this support were associated with place of delivery. Multivariate logistic regression analysis revealed that married women whose sisters-in-law helped them fetch water were less likely to deliver at health facilities. Bivariate analysis revealed that married women whose husbands supported them in farming and those whose neighbors helped them fetch water were also less likely to deliver at health facilities. These results are explained by the local cultural context. In the area of the study, women usually live near their husband's family after marriage, and mutual aid and collaboration with neighbors is quite common [26]. Having support from sisters-in-law, a husband or neighbors indicates stable relationships within the marriage, and with the husband's family and community. Our results showed that $44.8 \%$ of women who delivered at home were assisted by their mother-in-law (not TBA). Married women who had stable relationships with their in-laws readily received support to deliver at home, thereby decreasing their rate of facility delivery. Moreover, if a member of their husband's family recommends a home delivery to a married woman, it is difficult to act against such advice, since married women are under pressure from this side of the family. This supports the previously reported idea that social support can include negative support as well as positive support [27]. Some married women deliver at health facilities because of positive reasons such as 
Table 5 Associations between advice on facility delivery and place of delivery among married women

\begin{tabular}{llll}
\hline $\begin{array}{c}\text { Home } \\
\text { delivery } \\
(\mathrm{N}=54)\end{array}$ & & $\begin{array}{c}\text { Facility } \\
\text { delivery } \\
(\mathrm{N}=191)\end{array}$ & \\
\cline { 2 - 2 }$\%$ & & P $\%$ & P-value $^{a}$
\end{tabular}

Advised by mother-in-law

$\begin{array}{lrrrrr}\text { Yes } & 5 & 9.6 & 47 & 90.4 & \\ \text { No } & 49 & 25.4 & 144 & 74.6 & 0.015\end{array}$

Advised by father-in-law

Yes

No

$\begin{array}{rrrr}1 & 100.0 & 0 & 0.0 \\ 53 & 21.7 & 191 & 78.3\end{array}$

0.059

Advised by husband

$\begin{array}{lrrrr}7 & 7 & 14.9 & 40 & 85.1\end{array}$

No

$\begin{array}{llll}47 & 23.7 & 151 & 76.3\end{array}$

0.189

Advised by sister-in-law

$\begin{array}{lrrrrr}\text { Yes } & 0 & 0.0 & 3 & 100.0 & \\ \text { No }^{\text {b }} & 54 & 22.3 & 188 & 77.7 & 0.354\end{array}$

Advised by mother

$\begin{array}{lrrrrr}\text { Yes } & 1 & 10.0 & 9 & 90.0 & \\ \text { No } & 53 & 22.6 & 182 & 77.4 & 0.348\end{array}$

Advised by father

Yes

No

$$
0
$$

Advised by sister

$$
\text { Yes }
$$

$\mathrm{No}^{\mathrm{c}}$

Advised by neighbor

$\begin{array}{lrrrr}\text { Yes } & 2 & 40.0 & 3 & 60.0 \\ \text { No } & 52 & 21.7 & 188 & 78.3 \\ \text { Advised by health staff } & & & & \end{array}$

Advised by health staff

\begin{tabular}{lrrrrr} 
Yes & 27 & 17.4 & 128 & 82.6 & \\
No & 27 & 30.0 & 63 & 70.0 & 0.022 \\
\hline
\end{tabular}

${ }^{a}$ Chi-square test.

${ }^{b}$ Included women who did not have any sisters-in-law and who were therefore not advised to have a facility delivery by their sisters-in-law.

'Included women who did not have any sisters and who were therefore not advised to have a facility delivery by their sisters.

believing it is safer than home delivery. A previous study found that the perceived competency of midwives and better equipment were among the reasons women used childbirth services [5]. On the other hand, some married women who do not have a good relationship with their husbands or their neighbors might deliver at health facilities for negative reasons such as not having support for home delivery. Hence, facility delivery may be chosen for both positive and negative reasons.

The present study found that unmarried women whose mothers supported them in housework and whose sisters helped them fetch water were more likely to deliver at
Table 6 Associations between advice on facility delivery

\begin{tabular}{|c|c|c|c|c|c|}
\hline & \multicolumn{2}{|c|}{$\begin{array}{l}\text { Home delivery } \\
\qquad(\mathrm{N}=4)\end{array}$} & \multicolumn{2}{|c|}{$\begin{array}{l}\text { Facility delivery } \\
\qquad(\mathrm{N}=54)\end{array}$} & \multirow[b]{2}{*}{ P-value } \\
\hline & $\mathrm{N}$ & $\%$ & $\mathrm{~N}$ & $\%$ & \\
\hline \multicolumn{6}{|c|}{ Advised by mother } \\
\hline Yes & 1 & 4.3 & 22 & 95.7 & \\
\hline No & 3 & 8.6 & 32 & 91.4 & 0.535 \\
\hline \multicolumn{6}{|c|}{ Advised by father } \\
\hline Yes & 0 & 0.0 & 1 & 100.0 & \\
\hline No & 4 & 7.0 & 53 & 93.0 & 0.784 \\
\hline
\end{tabular}
and place of delivery among unmarried women

Advised by sister

$\begin{array}{lllcrrr}\text { Yes } & 0 & 0.0 & 1 & 100.0 & \\ \text { No } & \text { b } & 4 & 7.0 & 53 & 93.0 & 0.784\end{array}$

Advised by neighbor

$\begin{array}{lllcrrr}\text { Yes } & 0 & 0.0 & 1 & 100.0 & \\ \text { No } & 4 & 7.0 & 53 & 93.0 & 0.784\end{array}$

Advised by health staff

$\begin{array}{lllll}\text { Yes } & 2 & 7.1 & 26 & 92.9\end{array}$

No

2

$6.7 \quad 28$

$93.3 \quad 0.943$

${ }^{\mathrm{a} C h i-s q u a r e}$ test.

${ }^{b}$ Included women who did not have any sisters and who were therefore not advised to have a facility delivery by their sisters.

Table 7 Logistic regression analysis of factors associated with place of delivery among married women $(\mathrm{N}=\mathbf{2 4 5})$

\begin{tabular}{lll}
\hline Variable & $\mathrm{OR}^{\mathrm{a}}$ & $95 \% \mathrm{Cl}^{\mathrm{b}}$ \\
\hline Education level & &
\end{tabular}

0 : Primary and lower

1: Secondary/Nocational and above $\quad 2.5 \quad 1.0-6.1$

Economic status (Household asset score)

$0: \leq 3$

1: $\geq 4$

Medical insurance coverage

0 : No

1: Yes

Parity

0: Multiparous

1: Primiparous

Sister-in-law's support for fetching water

0 : Yes

1: No

Advice from family or neighbor to deliver at a health facility

0 : No

1: Yes

$2.5 \quad 1.2-5.5$

All variables were included in the logistic regression model.

${ }^{\mathrm{a}} \mathrm{OR}=$ odds ratio.

${ }^{\mathrm{b}} \mathrm{Cl}=$ confidence interval. 
health facilities. Unmarried women are of course not subject to pressure from a husband's family, and they can readily get support from their original family, so they are less likely to be influenced by traditional custom related to home delivery. As a result, unmarried women who had social support were more likely to deliver at health facilities.

The present multivariate analysis revealed that married women who were advised to deliver at a health facility by family or neighbors were more likely to do so than those who did not receive such advice. Bivariate analysis also showed that married women who were given such advice by their mother-in-law were more likely to deliver at a health facility than those who did not receive such advice. This suggests married women are more likely to be affected by advice from their mother-in-law than from any other family members. Mothers-in-law appear to be very influential regarding where their daughtersin-law deliver, and should therefore be involved with promotion of facility delivery. Moreover, married women who were advised by health staff to deliver at a health facility were more likely to do so than those who did not receive such advice, in agreement with a previous study [28]. However, the fact that women could receive advice from health staff suggests they already had good access to health services. Indeed, a previous study reported that professionals such as health care providers and counselors were not considered sources of social support by women [12]. Therefore, promotion of facility delivery should not accordingly be implemented only by health staff but also by close kinship.

\section{Limitations of the study}

Several limitations are worth noting. First, the respondents were mothers who brought their babies to the health center, raising the possibility of selection bias. Second, participants might have had recall bias about pregnancy and childbirth. Furthermore, women could have responded with socially desirable answers such as reporting that they considered facility delivery in a positive light. In addition, ascertaining support for housework, fetching water, and farming, and advice regarding facility delivery does not provide the whole picture of social support. We therefore measured only some of the instrumental and informational support available to women. Finally, we conducted multivariate analysis only for married women, because the number of unmarried women was inadequate. The generalizability of our findings may accordingly be limited.

\section{Conclusions}

In conclusion, our study found that social support was associated with place of delivery. This support took the form of instrumental support, such as support for daily tasks, and informational support, such as advice to deliver in a health facility. However, married and unmarried women differed in terms of the factors influencing their decision about where to deliver. Married women who had instrumental support were less likely to deliver at health facilities than those without this support. In contrast, unmarried women who had instrumental support were more likely to deliver at health facilities than those without this support. Married women who had informational support were also more likely to deliver at health facilities than those without such support. A woman's mother-in-law was the most influential person regarding place of delivery. We therefore need to recruit as advocates not only women of reproductive age but also those in the same generation as their mothers-in-law. These findings can be used by policy makers, planners, and health care professionals to take into account social support issues in improving health facility deliveries. Increasing the awareness of women and their family members about the benefits of facility deliveries are recommended.

\section{Additional files} Additional file 1: Questionnaire1: questions about socio-demographic
characteristics.

Additional file 2: Questionnaire2: questions about birth experience. Additional file 3: Questionnaire 3: questions about social support.

\section{Competing interests}

The authors declare that they have no competing interests.

\section{Authors' contributions}

$\mathrm{MO}$ conceived of the study, did the data collection and analysis, wrote the paper. SH and AM also wrote the paper. SH and MK contributed to the study design. All authors read and approved the final manuscript.

\section{Acknowledgments}

The Kericho East and West (Belgut) District Government and Sosiot Health Center facilitated this study in many ways. Moreover, we would like to acknowledge JICA and HANDS.

\section{Author details}

${ }^{1}$ Graduate School of Biomedical Sciences, Nagasaki University, 1-12-4 Sakamoto, Nagasaki 852-8523, Japan. ${ }^{2}$ Graduate School of International Health Development, Nagasaki University, Nagasaki, Japan. ${ }^{3}$ Centre for Public Health Research (CPHR), Kenya Medical Research Institute (KEMRI), Nairobi, Kenya.

Received: 4 May 2013 Accepted: 12 November 2013

Published: 21 November 2013

\section{References}

1. WHO, UNICEF, UNFPA and the World Bank: Trends in Maternal Mortality: 1990 to 2008. Geneva: WHO Press; 2010.

2. Campbell OMR, Graham WJ: Strategies for reducing maternal mortality: getting on with what works. Lancet 2006, 368(9543):1284-1299.

3. Koblinsky M, Matthews Z, Hussein J, Mavalankar D, Mridha MK, Anwar I, Achadi E, Adjei S, Padmanabhan P, Marchal B, De Brouwere V, van Lerberghe W: Going to scale with professional skilled care. Lancet 2006, 368(9544):1377-1386.

4. Osubor KM, Fatusi AO, Chiwuzie JC: Maternal health-seeking behavior and associated factors in a rural Nigerian community. Matern Child Health J 2006, 10(2):159-169.

5. Titaley $C R$, Hunter $C L$, Dibley MJ, Heywood P: Why do some women still prefer traditional birth attendants and home delivery?: a qualitative study on delivery care services in West Java Province Indonesia. BMC Pregnancy Childbirth 2010, 10:43. 
6. Danforth EJ, Kruk ME, Rockers PC, Mbaruku G, Galea S: Household decisionmaking about delivery in health facilities: evidence from Tanzania. $J$ Health Popul Nutr 2009, 27(5):696-703.

7. Wirth M, Sacks E, Delamonica E, Storeygard A, Minujin A, Balk D: "Delivering" on the MDGs?: equity and maternal health in Ghana, Ethiopia and Kenya. East Afr J Public Health 2008, 5(3):133-141.

8. Uchino BN: Social support and physical health: understanding the health consequences of relationships. New Haven: Yale University Press; 2004.

9. Kenya National Bureau of Statistics (KNBS) and ICF Macro: Kenya Demographic and Health Survey 2008-09. Calverton, Maryland: Kenya National Bureau of Statistics (KNBS) and ICF Macro; 2010.

10. Ministry of Public Health and Sanitation and Ministry of Medical Services, Republic of Kenya: National Reproductive Health Strategy 2009-2015. Nairobi; 2009.

11. Health and Development Service (HANDS), Japan International Cooperation Agency (JICA): Community Impact Assessment Survey SAMOKIKE Project. Nairobi: ALMACO Management Consultants Ltd; 2007.

12. Schaffer MA, Lia-Hoagberg B: Effects of social support on prenatal care and health behaviors of low-income women. $J$ Obstet Gynecol Neonatal Nurs 1997, 26(4):433-440.

13. Ransjö-Arvidson AB, Chintu K, Ng'andu N, Eriksson B, Susu B, Christensson K, Diwan VK: Maternal and infant health problems after normal childbirth: a randomised controlled study in Zambia. J Epidemiol Community Health 1998, 52(6):385-391.

14. Maimbolwa MC, Sikazwe N, Yamba B, Diwan V, Ransjö-Arvidson AB: Views on involving a social support person during labor in Zambian maternities. J Midwifery Womens Health 2001, 46(4):226-234.

15. Maimbolwa MC, Yamba B, Diwan V, Ransjö-Arvidson AB: Cultural childbirth practices and beliefs in Zambia. J Adv Nurs 2003, 43(3):263-274.

16. Madi BC, Sandall J, Bennett R, MacLeod C: Effects of female relative support in labor: a randomized controlled trial. Birth 1999, 26(1):4-8

17. Cobb S: Social support as a moderator of life stress. Psychosom Med 1976, 38(5):300-314.

18. House JS: Work stress and social support. Reading: Addison-Wesley Publishing Company, Inc; 1981

19. Schaefer C, Coyne JC, Lazarus RS: The health-related functions of social support. J Behav Med 1981, 4(4):381-406.

20. Mbizvo MT, Fawcus S, Lindmark G, Nyström L: Maternal mortality in rural and urban Zimbabwe: social and reproductive factors in an incident case-referent study. Soc Sci Med 1993, 36(9):1197-1205.

21. Ministry of Planning and National Development, Republic of Kenya: Kericho District - District Strategic Plan 2005-2010 for Implementation of the National Population Policy for Sustainable Development. Nairobi: National Coordination Agency for Population and Development; 2005.

22. van Eijk AM, Bles HM, Odhiambo F, Ayisi JG, Blokland IE, Rosen DH, Adazu K, Slutsker L, Lindblade KA: Use of antenatal services and delivery care among women in rural western Kenya: a community based survey. Reprod Health 2006, 3:2.

23. Hounton S, Chapman G, Menten J, De Brouwere V, Ensor T, Sombié I, Meda N, Ronsmans C: Accessibility and utilisation of delivery care within a Skilled Care Initiative in rural Burkina Faso. Trop Med Int Health 2008, 13(Suppl 1):44-52.

24. Hodgkin D: Household characteristics affecting where mothers deliver in rural Kenya. Health Econ 1996, 5(4):333-340.

25. Wagle RR, Sabroe S, Nielsen BB: Socioeconomic and physical distance to the maternity hospital as predictors for place of delivery: an observation study from Nepal. BMC Pregnancy Childbirth 2004, 4(1):8.

26. Komma T: Ghost and witchcraft as causes of misfotunes among the Kipsigis. The Hitotsubashi Review 1983, 90(5):667-683 (in Japanese).

27. Antonucci TC, Social supports and social relationships: In Handbook of aging and the social sciences. 3rd edition. Edited by Binstock RH, George LK. San Diego: Academic Press, Inc; 1990:205-226.

28. Mpembeni RN, Killewo JZ, Leshabari MT, Massawe SN, Jahn A, Mushi D, Mwakipa $\mathrm{H}$ : Use pattern of maternal health services and determinants of skilled care during delivery in Southern Tanzania: implications for achievement of MDG-5 targets. BMC Pregnancy Childbirth 2007, 7:29.

doi:10.1186/1471-2393-13-214

Cite this article as: Ono et al:: Association between social support and place of delivery: a cross-sectional study in Kericho, Western Kenya. BMC Pregnancy and Childbirth 2013 13:214.

\section{Submit your next manuscript to BioMed Central and take full advantage of:}

- Convenient online submission

- Thorough peer review

- No space constraints or color figure charges

- Immediate publication on acceptance

- Inclusion in PubMed, CAS, Scopus and Google Scholar

- Research which is freely available for redistribution 